\title{
Should there be a recommended limit to the number of references in a scientific article?
}

TO THE EDITOR: The existence of quite fast and accurate means of written communication has definitely contributed to the remarkable development in Medicine this century. The increased number of scientific works published as a result of the medical investigation quality enhancement has triggered the need for changes in the work style itself, which should be concisely written and well structured. The space reserved for publications in journals is to o valuable to be wasted in redundancies and fastidiousness. Likewise, the time available for reading is short, explaining why a clear and objective article results in an asset to the reader. However, a medical scientific publication should also bring enough information for readers to be able to: 1 . Repeat the described procedures; 2 . A ssess the Author's observations, and 3. Assess the intellectual processes developed by the author of the report. ${ }^{1}$ Therefore, data should be as full as possible and the sources from which the author based his ideas should be clearly referred to.

In the São Paulo Medical Journal's Instructions we come across a limitation to the number of References for given types of articles i.e. Brief $\mathrm{C}$ ommunications, Case Report and Letter to the Editor, with a maximum of only four being set. 0 bviously such types of articles require fewer corroborating data and a smaller number of quotations, given the character of the description itself; however, now and then the case report may be more complex or of scientific relevance, deserving the triggering of an intellectual process, based on multiple sources and previous case reports, which should be quoted and without which there would be the risk of inaccuracy or lack of reliability.

It seems clear that there should be an ideal number of allowed references. Their excess is currently not desirable, as this may even account for more doubt than actual erudition or conviction on the part of the reporter. However, on the other hand the lack or curtailment of such referencer may impair correct interpretation or even repetition of the clinical experiment.

In relation to such remarks it seems suitable to quote A ristotle - "In M edio Virtus!" - Therefore, good sense should prevail. The author must be clear, concise, objective. The Journal, through the required and attentive work of its Editor and Reviewers, is in a position to control and guide the Author who has forwarded his/ her paper, heeding the Instructions requirements. And a useful exchange of information results from this reciprocal contact, allowing for the enhancement of the finished product - The Published Paper. 
This dialogue is imperative and of ultimate relevance for the improvement of articles and as a result, for the Journal to be fully successful.

Thus, by proposing such a debate, we suggest that the number of references allowed for the above mentioned types be no longer limited, but rather that the reviewer's criteria should prevail, taking into account the importance or relevance of the matter described. Such is our proposition.

\section{Jaime Anger}

\section{REFERENCE}

1. Day RA. - Cómo escribir y publicar trabajos científicos. The Oryx Press, Washington, 1990.

IN RESPONSE: Responding to the question "should there be a recommended limit to the number of references in a scientific article?": without doubt, the answer is yes! In the authors' discussion, they have already found the answer: good sense is the final word. And the Journal has been acting within this spirit, recommending the general lines of how articles should appear, and when necessary, giving individual evaluation to the article in question.

The recommendations of the Journal are not limited to the number of citations, butalso refer to the number of pages, figures and other items of the structure and contents of the article. By doing this, we are improving the quality (form and content) of the Journal still further. These rules follow the recommendations of the International Committee of Medical Journal Editors ${ }^{1}$ and also the recommendations for the statistical content, ${ }^{2}$ which authors should be familiar with before starting to compose their manuscripts.

To conclude by citing Day ${ }^{3}$ regarding the characteristics of a study, in recent times such characteristics have been evolving into a nother three: validity, importance and applicability, ${ }^{4}$ to permit the reader to evaluate an article.

It is always opportune for authors and readers of the Journal to discuss aspects of the norms adopted by the Journal, and such feedback is always beneficial.

\section{Aldemar Araujo Castro, MD, MChir \\ Deputy Editor}

\section{REFRENCES}

1. International Committee of Medical Journal Editors. Uniform requirements for manuscripts submitted to biomedical journals. Ann Intern Med 1997;126(1):36-47.

2. Altman DG; Gore SM; Gardner MJ; Pocock SJ. Statistical guidelines for contributors to medical journals. Br Med J (Clin Res Ed) 1983;286(6376):1489-93.

3. Day R. How to write and publish a scientific paper. 4th edition. Phoenix: Oryx Press; 1994.

4. Oxman AD, Sackett DL, Guyatt GH. Users' guides to the medical literature. I. How to get started. The Evidence-Based Medicine Working Group. JAMA 1993;270(17):2093-5.

Conflict of Interest: Deputy Editor of the São Paulo Medical Journal. 